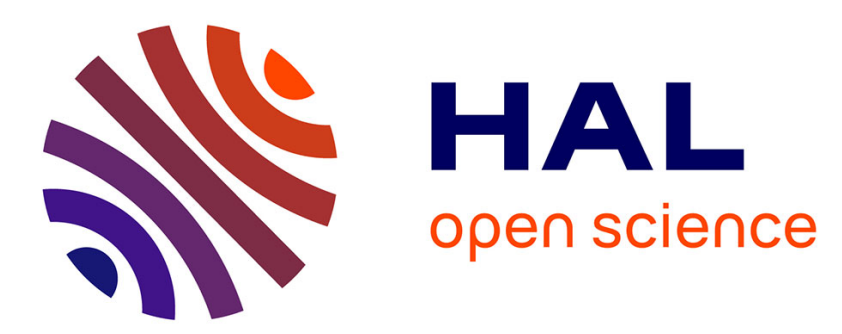

\title{
X-ray topographic evidence of an asymmetrical pre-yield behaviour in indium antimonide
}

\author{
R. Kesteloot, J. Di-Persio
}

\section{To cite this version:}

R. Kesteloot, J. Di-Persio. X-ray topographic evidence of an asymmetrical pre-yield behaviour in indium antimonide. Journal de Physique Lettres, 1980, 41 (11), pp.259-262. 10.1051/jphyslet:019800041011025900 . jpa-00231774

\section{HAL Id: jpa-00231774 https://hal.science/jpa-00231774}

Submitted on 1 Jan 1980

HAL is a multi-disciplinary open access archive for the deposit and dissemination of scientific research documents, whether they are published or not. The documents may come from teaching and research institutions in France or abroad, or from public or private research centers.
L'archive ouverte pluridisciplinaire HAL, est destinée au dépôt et à la diffusion de documents scientifiques de niveau recherche, publiés ou non, émanant des établissements d'enseignement et de recherche français ou étrangers, des laboratoires publics ou privés. 


\title{
X-ray topographic evidence of an asymmetrical pre-yield behaviour in indium antimonide
}

\author{
R. Kesteloot and J. Di-Persio \\ Laboratoire de Structure et Propriétés de l'Etat Solide (*), Université des Sciences et Techniques de Lille, \\ 59655 Villeneuve d'Ascq Cedex, France
}

(Reçu le 4 mars 1980, accepté le 11 avril 1980)

\begin{abstract}
Résumé. - Deux échantillons identiques et presque parfaits d'InSb sont déformés par compression jusqu'au point de contrainte maximale ; l'un étant griffé sur une face, l'autre sur son opposée. L'asymétrie du comportement macroscopique résultant (cas mou et $d u r$ ) est visible dans la sous-structure de dislocations développée, mise en évidence par topographie aux rayons X. Cette asymétrie est discutée en considérant l'introduction par abrasage de sources de surface de natures différentes $\alpha$ ou $\beta$.
\end{abstract}

\begin{abstract}
Two identical nearly perfect InSb samples have been deformed by compression up to the maximum yield point, one sample being ground on one face, the other on its opposite. The resulting asymmetrical macroscopic behaviour (soft and hard cases) appears to reflect in the dislocation substructure so far developed, as revealed by X-ray topography. This asymmetry is discussed in terms of a different $\alpha$ or $\beta$ nature of the surface sources introduced by grinding.
\end{abstract}

1. Introduction. - Recently, J. L. Farvacque and D. Ferré $[1,2]$ reported on an experimental investigation of the plastic behaviour of indium antimonide single crystals tested in uniaxial compression and showed that, under suitable conditions, the behaviour is asymmetric. For a given orientation, carefully chosen in order to favour single slip on the highest stressed (111) plane, deformation tests were performed at the same traverse speed on two sets of geometrically identical samples, cut simultaneously from the same nearly perfect as-grown crystal. The only difference was for one set of samples to be mechanically abraded on one single face, and the other one on its opposite [1]. An asymmetrical behaviour was thus made clearly apparent, both from a comparison of deformation curves which indeed showed definite differences between the two sets of samples as regards the values of the resolved shear stress at upper as well as at lower yield points, and from a careful experimental determination of the activation parameters, enthalpy and volume, which resulted into a net difference in $\Delta G$ for the two cases. This circumstance allowed the authors to define a soft case and a hard case [1], with activation energies of $0.6 \mathrm{eV}$

$\left(^{*}\right)$ Associé au C.N.R.S. no 234. and $1.1 \mathrm{eV}$ respectively. Because of the identical sample orientations, this asymmetrical behaviour has been merely attributed to some specific properties of surface sources thus introduced. On this basis, a crude model has been proposed, based on the different character, $\alpha$ or $\beta$, of opposite segments of a dislocation loop in the InSb structure when of $60^{\circ}$ type. Provided that only surface sources are present in the samples at the onset of deformation, either $\alpha$ or $\beta$ dislocations should be introduced by grinding specific faces [2], and subsequently develop and multiply throughout the sample, under the applied stress. The observed macroscopic behaviour should reflect the different mobilities of $\alpha$ and $\beta$ dislocations which do not experiment the same lattice friction.

In order to ascertain this hypothesis, a direct observation of the dislocation substructure developed in both the soft and hard cases as function of stress is needed. A previous electron microscopy study by J. L. Farvacque (unpublished results) of thin slices cut from samples deformed up to the lower yield point has shown in the soft case, relatively few long screw dislocations, and in the hard case, complicated tangles including both screw and $60^{\circ}$ dislocations. However, the small size of slices used in electron microscopy and the importance of image 
forces do not guarantee an exact representation of the dislocation substructure developed in the bulk. Because of the quite low initial dislocation density of the as-grown crystal $\left(<10^{2} \mathrm{~cm} / \mathrm{cm}^{3}\right)$, X-ray Lang transmission topography [3] is obviously an adequate tool here, at least to follow the evolution of the substructure up to the upper yield point, for which it was believed that the density of dislocations would be still low enough for this technique to apply [4].

The present note reports on a preliminary investigation of the dislocation substructure thus developed in the soft and the hard cases at upper yielding, as part of an extensive study of the pre-yield domain in InSb, in various conditions of stress and temperature, and in connection with the above mentioned asymmetrical behaviour.

2. Experimental results. - Two identical samples, $(4 \times 4 \times 14) \mathrm{mm}^{3}$ large, have been deformed by compression on an Instron machine, up to the upper yield point, at a temperature of $240{ }^{\circ} \mathrm{C}$ and a traverse velocity of $10 \mu \mathrm{m}$ per minute $\left(\dot{\varepsilon}=1.2 \times 10^{-5} \mathrm{~s}^{-1}\right)$. The sample geometry and the corresponding deformation curves are shown on figure 1. Curve 1 (hard case) relates to the sample abraded on face $B$. Curve 2 (soft case) relates to the sample abraded on face A.

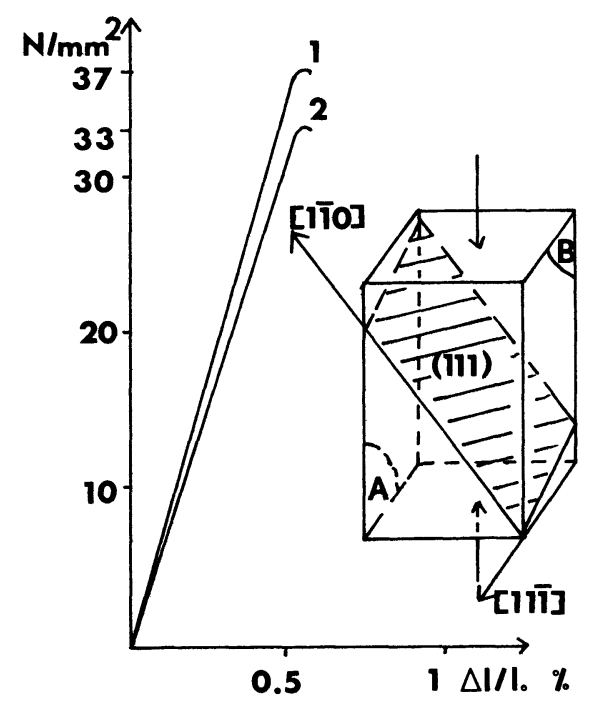

Fig. 1. - Sample geometry and deformation curves $\left(T=240^{\circ} \mathrm{C}\right)$. 1) hard case - (abraded B face) ; 2) soft case - (abraded A face).

Slices, one millimeter thick, have been cut from the deformed samples parallel to the effective (111) slip plane, as revealed by optical microscopy. These slices have been then chemically polished down to a thickness of about 200 microns.

The X-ray Lang topographic study was performed with the help of a high power rotating anode X-ray generator $(12 \mathrm{~kW})$. Silver $\mathrm{K}_{\alpha}$ radiation was selected because of the high absorption coefficient of $\mathrm{InSb}$ $\left(\mu_{0}=92 \mathrm{~cm}^{-1}\right.$ for $\mathrm{AgK}_{\alpha}$; for a slice $200 \mu \mathrm{m}$ thick, this gives a $\mu_{0} . t$ value of about 2). $\{111\}$ and $\{220\}$ reflections were used, which allowed for a complete determination of Burgers vectors and directions of dislocation lines. Photographs $2 a$ and $b$ are typical examples of configurations observed in (a) the soft case and $(b)$ the hard case. For the ease of discussion the traces of the abraded faces have been also indicated.

- In the soft case (Fig. 2a), essentially one single slip system is observed. It corresponds to the expected $1 / 2$ [110] (111) one, with a 0.47 Schmid factor. An homogeneous density of long straight lines which

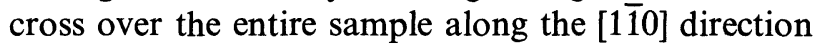
are clearly evidenced. They merely correspond to long screw dislocations with $1 / 2$ [1ㅣㅣ $]$ Burgers vector, as characterized by other topographs taken with different reflections. However, their density is too high for each one to be finely resolved.

- In the hard case (Fig. 2b), three slip systems are easily distinguished. They are namely :

- The primary $1 / 2$ [110] (111) slip system with a 0.47 Schmid factor.

- The secondary $1 / 2$ [011] (111) slip system with a 0.36 Schmid factor, that is the primary plane but a secondary slip direction.

- The third $1 / 2$ [110] (11)1) slip system with a 0.36 Schmid factor. The (111) plane is inclined with respect to the (111) faces of the slices.

These glide elements are summarized on the stereographic projection shown in figure 3 .

The primary $1 / 2[1 \overline{10}]$ (111) slip system is extinguished on figure $2 b$. (This topograph has been choosen for publication because it evidences clearly both secondary slip systems.) Other topographs show it with long $1 / 2$ [1ㅣㅣ screw dislocations but with a quite low and non uniform density.

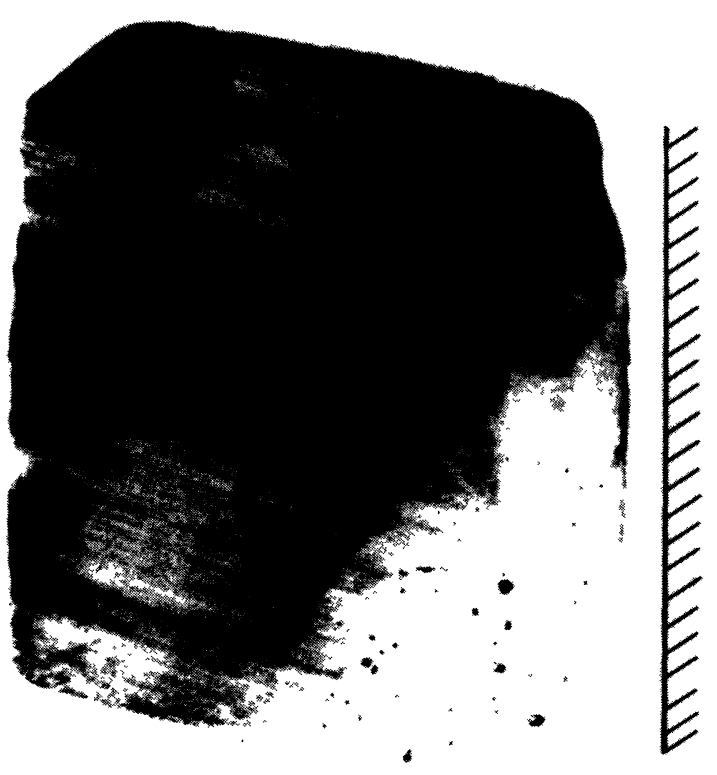

Fig. $2 a$. - Soft case. $(\overline{1} 11)$ reflection $(\times 30) .1 / 2[1 \overline{1} 0]$ screw dislocations. 


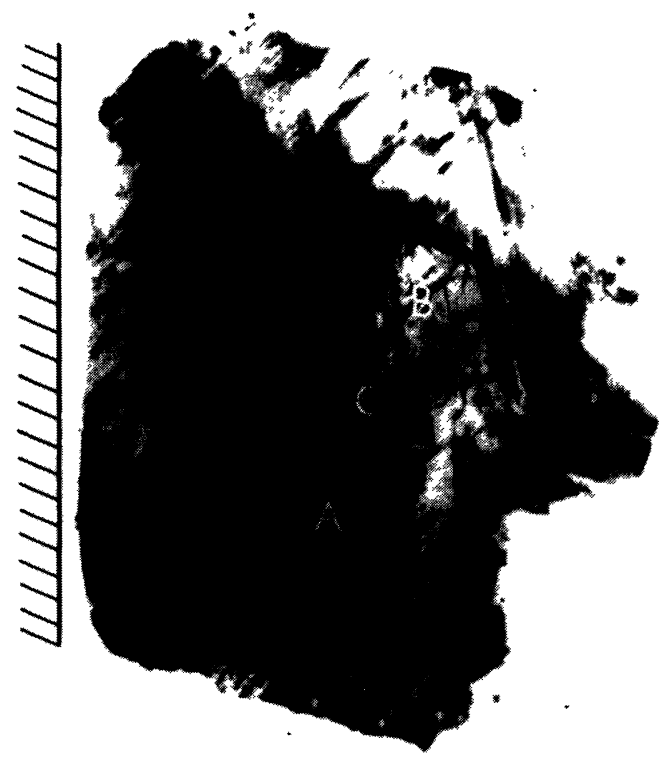

Fig. 2b. - Hard case $(11 \overline{1})$ reflection $(\times 30)$. A : secondary $1 / 2$ [011] (111) slip system; B : secondary $1 / 2$ [110] (111) slip system; $\mathrm{C}$ : internal sources.

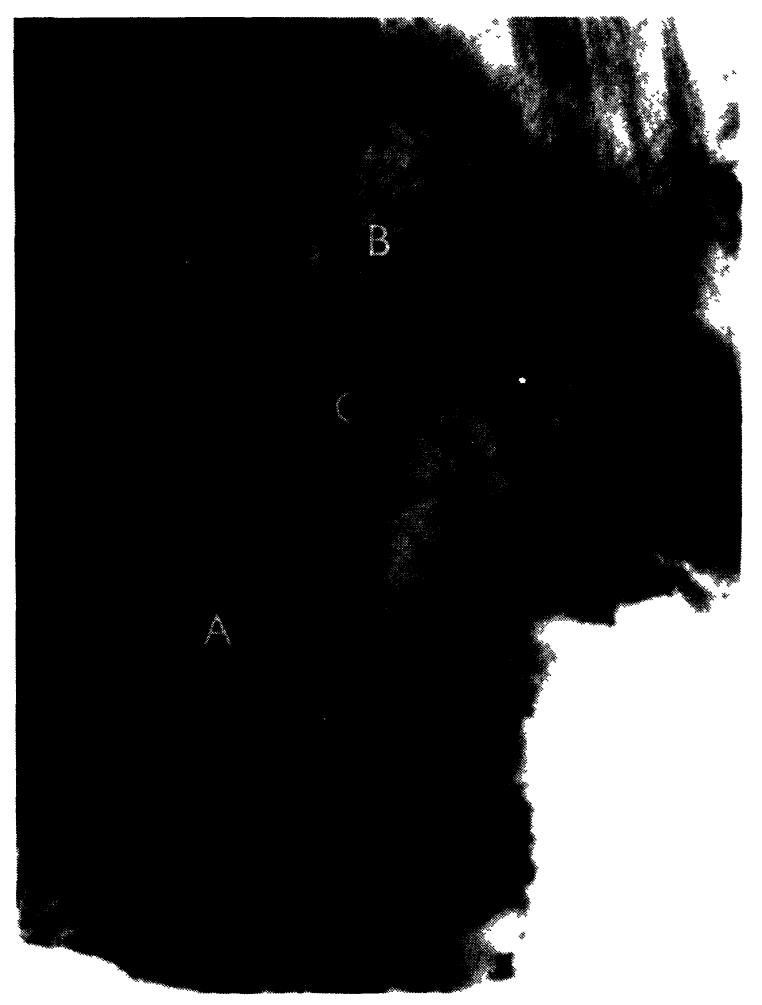

Fig. $2 c$. - Figure $2 a$ enlargement $(\times 60)$.

The secondary $1 / 2$ [011] (111) slip system is on the other hand very dense and of the same character as the primary one, that is, it consists of long screw dislocations which, as figure $2 b$ shows, extend only from the ground side of the sample. This distribution is therefore very homogeneous. We therefore found a close correlation between the observed distribution

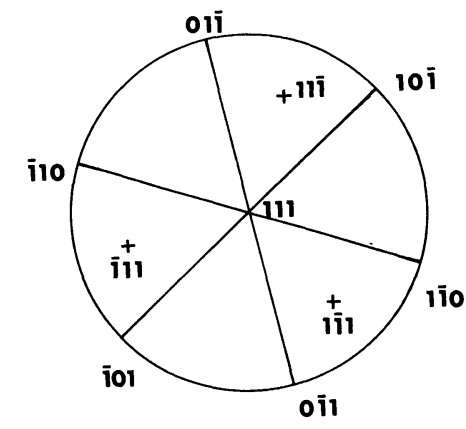

Fig. 3. - Corresponding stereo projection.

and the hypothesis of dislocation sources emitted from the surface along that direction. The third $1 / 2$ [110] (11̄1) slip system presents again similar features as above. In addition, a number of internal sources, clearly individualized on this topograph, appear to belong to this system ( $C$ in figure $2 b$ ).

3. Discussion. - This preliminary X-ray topographic investigation shows a clear difference with regard to the nature of slip systems which operate in both cases in the pre-yield domain. Although, in the hard case, secondary slip systems may not play a major role in the macroscopic plasticity, their presence at this stage of deformation clearly indicates different pre-yield behaviours, which have to be related to the nature of emitting sources. X-ray topographic examination of the dislocation content in the starting as-grown material reveals quite a low density, less than $70 \mathrm{~cm} / \mathrm{cm}^{3}$, so the structures observed in deformed samples cannot be accounted for by multiplication from internal sources. Internal sources would develop closed loops for which both $\alpha$ and $\beta$ characters are simultaneously present, unable to yield an overall asymmetrical behaviour. This is probably the reason why it has not been observed in previous works. Thus, it becomes quite obvious that the observed asymmetry must be related to the nucleation and expansion of half loops with either an $\alpha$ or $\beta$, or screw character, generated at surfaces and moving into an otherwise perfect crystal, in accordance with the proposed model [1]. Its basic feature is to assume that $\alpha$ dislocations are more mobile than $\beta$ ones [5]. Let us analyse further this proposal. Suppose that in the soft case (Fig. 2a), half loops created by grinding are say of $\alpha$ character. Under applied stress, these $\alpha$ dislocations will start to move, leaving behind long screw dislocations, homogeneously distributed throughout the sample if the grinding operation has been made itself homogeneous. This situation might be then that depicted on figure $2 a$. Only the $1 / 2[1 \overline{1} 0]$ (111) slip system will be operative there, because of the very favourable Schmid factor for this system (0.47).

Conservely, in the hard case (Fig. 2b), half loops should then be say of $\beta$ character. In order to acco- 
modate the same deformation rate, a higher stress is now needed to move those $\beta$ dislocations at the required velocity. This may account for the different deformation curve obtained (Fig. 1), with a higher upper yield point. Of course, this higher stress can also initiate secondary soft slip systems with less favourable but still appreciable Schmid factors (0.36), as observed in figure $2 b$. In particular, the secondary $1 / 2$ [011] (111) slip system is of interest here because of the nature of leading $60^{\circ}$ dislocations which, by symmetry, appear to be of $\alpha$-type when emitted from the ground face, in the [0 $\overline{1} 1]$ direction. This explains reasonably the observed long screw dislocations belonging to this system and their heterogeneous distribution closely related to the projection of the abraded surface, along this slip direction.

The origin of the primary $1 / 2$ [1ㅣㅣ (111) slip system, which is here much less pronounced than in the soft case, is not so clear. Also composed of long screw dislocations, it might result from the motion of $\beta$ dislocations starting from the ground B face (Fig. 1) under the high stress experienced at the upper yield point. But it might also result from $\alpha$ dislocations emanating from the opposite non-ground face, just because any surface is never structurally perfect. Topographs seem to indicate that this second interpretation is at least partly valid.

Finally, the origin of the third $1 / 2$ [110] (11i1) system is still unsolved. For this system, half loops would normally expand as $\beta$ hard dislocations from the abraded B face. However, the very sparse nature of its distribution, as figure $2 b$ shows, would indicate rather that it originates from internal sources which, at the stress level considered, can begin to operate. A number of internal isolated sources belonging to this system are clearly seen in figures $2 b, 2 c$. In some cases, individual dislocations can be resolved, which are composed of short screw segments together with $60^{\circ}$ parts. Its spatial distribution, closely related to that of the above secondary slip system, indicate that internal sources may also originate from specific reactions between preexisting moving dislocations of other systems.

Acknowledgments. - The authors are indebted to Prof. B. Escaig, Dr. J. L. Farvacque and Miss D. Ferré for stimulating discussions.

\section{References}

[1] Ferré, D. and Farvacque, J. L., Phys. Status Solidi (a) 49 (1978) 737.

[2] Ferré, D. and Farvacque, J. L., J. Physique Colloq. 40 (1979) C6-157.

[3] LANG, A. R., Acta Crystallogr. 12 (1959) 249.
[4] LANG, A. R., Modern Diffraction and Imaging Techniques in Materials Science, Eds. S. Amelinckx, R. Gevers, G. Remaut and J. van Landuyt (North Holland, Amsterdam) 1970, p. 407-79.

[5] Erofeeva, S. A. and Osip'yan, Y. A., Fiz. Tver. Tel. 15 (1973) 772. 